\title{
Estudos sobre branquitude e branqueamento no Brasil
}

\author{
Audauto Garcia de Jesus Junior 1
}

Carone, I. \& Bento, M. A. S. (Orgs.). (2002). Psicologia social do racismo. Petrópolis: Vozes, 189 p.

A Psicologia Social no Brasil se caracteriza por seu afastamento, quando não ausência, das questões raciais e suas conseqüências na estrutura psíquica individual ou coletiva da população envolvida no contexto da discriminação, seja no papel de vítima ou agente discriminador. Raimundo Nina Rodrigues iniciou um trabalho pioneiro sobre a população negra no Brasil há mais de 100 anos. Porém, muito pouco tem-se realizado desde então, no tocante a estudos que investigam os fenômenos psicológicos que permeiam as relações sociais e abrangem questões raciais. Diante das lacunas deixadas pelas ciências sociais em relação a tais temas, torna-se importante que a Psicologia Social participe mais ativamente na produção de conhecimento que venha contribuir para o processo de construção da identidade coletiva da sociedade brasileira.

O livro a que esta resenha se refere trata-se de um esforço significativo de contribuição neste sentido. Os capítulos são de autoria de diversos pesquisadores, e o trabalho foi organizado por Iray Carone e Maria Aparecida Silva Bento.

A obra é composta por um prefácio e 9 capítulos, escritos por sete pesquisadoras, incluindo as organizadoras, e o prefácio foi escrito por Kabengele Munanga e busca justificar a relevância do tema do preconceito racial, contextualizando-o no cenário da história político-social brasileira, bem como das ciências sociais, especialmente a Psicologia.

Os capítulos do livro são o resultado de um projeto integrado, apresentado por uma de suas organizadoras como "O maior empreendimento científico de compreensão das relações raciais no Brasil" (cap. 1). Cada capítulo retrata a contribuição da pesquisa de um dos vários participantes envolvidos no projeto, como resultado quer de levantamentos de dados bibliográficos e da mídia em geral, quer de pesquisas de campo. Os textos apresentam, ainda, notas informativas de rodapé e, ao final de cada um deles, referências bibliográficas.

O título do primeiro capítulo é Breve bistórico de uma pesquisa psicossocial sobre a questão racial brasileira, de autoria de Iray Carone, e apresenta dados da história do racismo no Brasil. Seu objetivo é trazer informações sobre o desenvolvimento do projeto integrado de pesquisa que deu origem aos temas do livro, informando, na seqüência, dados como os autores de cada capítulo, seus respectivos enfoques e ainda um breve comentário sobre cada tema.

O capítulo seguinte (capítulo 2), escrito por Maria Aparecida Silva Bento, trata do tema Branqueamento e branquitude no Brasil, explorando as questões relacionadas ao padrão ideal de branqueamento, fornecido pela elite branca à sociedade, e projetado como um problema do negro. Este padrão retrata uma estratégia de proteção (um pacto social) dos privilégios da dinâmica racista para a classe branca, advindos de interesses e medos, produzidos no espaço do enfrentamento e constatação do outro, ou seja, das demais raças. Aborda também o conceito de branquitude como as características da identidade racial do branco brasileiro, suas estratégias e mecanismos de preservação da situação discriminante.

Porta de vidro: entrada para a branquitude é o título do capítulo 3, de autoria de Edith Piza, e fornece dados de uma pesquisa que buscou captar a percepção de mulheres brancas em relação a negras. As idéias que levaram a autora a pesquisar este aspecto das relações sociais racistas vieram por meio da constatação de que o branco não se posiciona e sequer se reconhece como agente no processo discriminatório. O negro é evidenciado como raça, focalizado em estudos partindo da visão do branco, enquanto este último se coloca numa posição de "invisibilidade", não se identificando como raça e parte responsável na relação preconceituosa. Em seguida, o texto analisa dois exemplos das vinte entrevistas realizadas pela autora com mulheres brancas.

O capítulo $4-A$ cor nos censos brasileiros, retrata um trabalho de levantamento de informações a respeito dos recenseamentos no Brasil e como eles refletiram, por meio de ausência ou presença de itens, o processo de auto e heteroatribuição de cor na realidade social do Brasil. Edith Piza e Fúlvia Rosemberg discutem o movimento que envolve a questão do pertencimento racial como construção cultural e os critérios de coleta censitários ao longo da história, que evidenciam a relação da identidade racial e sua construção com a forma como os indivíduos se autoclassificam em termos de cor.

Rosa Maria Rodrigues dos Santos faz uma

Endereço para correspondência:

${ }^{1}$ E-mail: agjjunior@hotmail.com 
reflexão de questões sobre origem étnica e suas influências na constituição da subjetividade, trazendo no capítulo 5, intitulado De café e de leite..., o relato da convivência com uma menina que apresentava problemas emocionais, no período de estágio realizado pela autora em instituição especializada em tratamento de crianças. São apresentadas informações sobre o quadro clínico, a intervenção e o progresso do caso, privilegiando o espaço de oficinas, especialmente a de artes, e considerações por meio de um enfoque psicanalítico.

O sexto capítulo, de Lia Maria Perez B. Baraúna, foi escrito com base na experiência de uma pesquisa sobre a visão do próprio negro em relação a sua posição na sociedade racista. À flor da pele, portanto, é um texto que reflete o resultado de várias entrevistas com negros, buscando captar em diferentes ângulos o universo dos aspectos ideológicos que embasam as relações discriminatórias, etnocêntricas e preconceituosas. Além disso, o capítulo descreve um exercício que buscou refinar o modelo de entrevistas da pesquisa, apresentando, como exemplo, duas entrevistas aplicadas de maneiras distintas. A primeira, conduzida com base num roteiro preestabelecido, e a segunda, aberta.

Em seguida, no capítulo 7, intitulado Branquitude - o lado oculto do discurso sobre o negro, Maria Aparecida Silva Bento escreve a respeito da experiência da aplicação do curso de relações raciais de uma organização não-governamental em instituições e sindicatos. A autora faz reflexões sobre as manifestações da desigualdade racial que estão camufladas na sociedade, analisando a realidade de um curso que abrange, num mesmo espaço, pessoas de diferentes etnias, assim como as dificuldades e resistências inerentes a este contexto de enfrentamento.
São apresentadas, também, informações sobre o conteúdo e a metodologia do curso.

O oitavo capítulo (Faíscas elétricas na imprensa brasileira: a questão racial em foco), sob autoria de Iray Carone e Isildinha Baptista Nogueira, constitui uma análise de como a imprensa brasileira elabora a questão racial e como isso é apresentado nos meios de comunicação jornalísticos. As autoras selecionaram três assuntos que estiveram em evidência nas notícias veiculadas à sociedade, com base num trabalho de recorte de notícias, artigos e comentários da imprensa brasileira dos anos 90, que pudessem demonstrar indícios de como o negro é mostrado e pensado neste contexto.

O último capítulo do livro, $A$ flama surda de um olhar, foi escrito por Iray Carone e se constitui, como a própria autora registra, em homenagem póstuma a Eduardo de Oliveira e Oliveira, militante negro de São Paulo e que deixou material rico sobre aspectos subjetivos da ideologia racial, em relatórios e documentos recolhidos ao longo da preparação de sua dissertação de Mestrado, na década de 70 .

Essa obra é recomendada a leitores interessados pela psicologia social, mais especificamente a quem procura informações sobre o perfil da desigualdade racial e suas conseqüências individuais e coletivas na sociedade brasileira. Os textos compilados oferecem uma ampla visão, sob vários ângulos, das influências de ideologias discriminatórias racistas na construção e afirmação de uma identidade nacional e seu mapeamento. A linguagem facilita a compreensão e a diversidade de temas correlatos, enriquecendo o livro como um todo. Concluímos que trabalhos desta natureza são necessários e relevantes para a psicologia social.

Sobre o autor:

Adauto Garcia de Jesus Junior é pedagogo, especialista em Psicopedagogia e mestrando em Psicologia pela Universidade São Francisco. 